\title{
O VALOR DA JUSTIÇA NA OBRA DE KELSEN*
}

\author{
THE VALUE OF JUSTICE IN KELSEN'S WORK
}

Mario G. Losano*

\begin{abstract}
RESUMO: ao discutir o valor da justiça na obra de Kelsen, este artigo visa a delinear argumento analisando o mencionado valor por meio do prisma epistemológico adotado pelo teórico do direito em questão, especialmente em sua Teoria pura do direito. Embora tenha elaborado escritos sobre política, teoria da justiça e assim por diante, eles não foram considerados parte de sua teoria jurídica, visto estar baseada em compreensão restrita do direito como validade. De acordo com ela, ainda que reflexões sobre a justiça sejam de grande importância à filosofia, à moral e à política, não têm significância ao direito e sua teoria pura.
\end{abstract}

PALAVRAS-CHAVE: Kelsen. Teoria pura do direito. Validade. Valor da justiça.

ABSTRACT: Discussing the value of justice in Kelsen's work, this article aims to expound an argument which analyses the mentioned value through the epistemological prism adopted by the specified law theorist, especially in his Pure Theory of Law. Even though he has written essays on politics, theory of justice, and so on, they have not been considered part of his legal theory since it was based on a restricted understanding of law as legal validity. According to it, even if reflections on justice are of great importance to philosophy, morals and politics, they have no significance to law and its pure theory.

KEYWORDS: Kelsen. Legal Validity. Pure Theory of Law. Value of Justice.

ÍNDICE: 1 A posição da justiça em uma teoria avalorativa do direito 2 Kelsen e o valor da justiça 3 Justiça e certeza do direito 4 Um exemplo de contraste entre teorias opostas da justiça: Kelsen e Cossio.

\section{A POSIÇÃO DA JUSTIÇA EM UMA TEORIA AVALORATIVA DO DIREITO}

Por questão de brevidade, enuncio alguns axiomas sobre a doutrina pura do direito que considero partilhados pela maioria da comunidade científica.

\footnotetext{
Conferência apresentada em Atenas a 12 de abril de 2013, nas dependências da Akadimìa Athenòn Akademie von Athen, no âmbito do congresso Hans Kelsen zum Gedenken: Die Aktualität eines großen Rechtswissenschaftlers und Soziologen des 20. Jahrhunderts [Hans Kelsen em memória: a atualidade de um grande cientista do direito e sociólogo do século XX (N. do T.)]. O texto está publicado em grego (LOSANO, 2013a) e no prelo em alemão. Tradução de Judá Leão Lobo, mestrando vinculado ao PPGD/UFPR e integrante do Núcleo História, Direito e Subjetividade. Revisão técnica de Ricardo Marcelo Fonseca, professor da Faculdade de Direito e do PPGD/UFPR e integrante do Núcleo História, Direito e Subjetividade.

** Professor emérito de filosofia do direito e de informática jurídica; professor na Escola de Doutorado em Direito da Universidade de Turim.

Revista da Faculdade de Direito - UFPR, Curitiba, vol. 59, n. 2, p. 31-45, 2014.
} 
Em primeiro lugar, no contexto das teorias da ciência, a doutrina pura do direito se localiza entre as doutrinas avalorativas, ou seja, as teorias que se propõem a descrever o próprio objeto e não a lhe atribuir um entendimento tido por melhor que outros, propondo-se a fazer ciência e não se apresentando como uma filosofia, um credo, uma ética. Daí a aversão de Kelsen a toda forma de jusnaturalismo, a toda forma de direito acima ou fora do Estado.

Em segundo lugar, no contexto das teorias gerais do direito, a doutrina pura se enquadra entre as doutrinas normatistas e, em particular, legalistas, ou seja, entre as teorias gerais considerando como próprio objeto somente o direito positivamente existente, especialmente o direito que assumiu a forma da lei (da norma jurídica geral e abstrata emanada de órgãos estatais para tanto designados pela constituição). Daí a aversão de Kelsen ao sincretismo metodológico, à confusão de métodos e temas sociológicos, políticos etc., na construção de uma teoria do direito.

Em terceiro lugar, a visão puramente formal do direito leva Kelsen a excluir toda consideração de conteúdo do estudo científico do direito: sua pirâmide normativa é constituída por proposições prescritivas coligadas entre si apenas por delegação de validade e por proposições descritivas coligadas entre si apenas por regras da lógica. Os valores, assim, são expurgados da doutrina pura do direito como elementos irracionais, não cognoscíveis segundo critérios racionais (i.e., lógicos), e, portanto, aceitáveis segundo escolhas emotivas, mas não apreensíveis por instrumentos científicos. "A justiça absoluta - escreve Kelsen (1960, p. 401) - é um ideal irracional porque pode derivar apenas de uma autoridade transcendente, isto é, de Deus" e, por isso, revela-se "uma eterna ilusão"1.

Partindo desses axiomas, a teoria geral do direito proposta por Kelsen exclui toda consideração acerca do valor da justiça por não ser cognoscível cientificamente, por não ser estatuído pelo poder legislativo estatal e por ser objeto de adesão irracional, ou seja, fideística. De outra parte, sua teoria se propõe a estudar o direito (positivo) assim como é, mas não pode ignorar que esse direito positivo é instituído para realizar certo valor de justiça. A doutrina pura supera esse impasse indicando o estudo da justiça não como objeto da ciência jurídica, mas de outras disciplinas, que - como a sociologia, a ciência política, a teologia etc. - têm igual dignidade científica, mas não devem ser confundidas com a ciência jurídica. Com efeito, Kelsen dedicou algumas obras à justiça ${ }^{2}$, assim como escreveu estudos de ciência política,

\footnotetext{
1 "Die absolute Gerechtigkeit [- schreibt Kelsen -] ist ein irrationales Ideal. Denn sie kann nur von einer transzendentales Autorität, nur von Gott ausgehen": [daher ist sie eine] "ewige Illusion".

${ }^{2}$ As primeiras edições das principais obras de Kelsen sobre a justiça são: Die platonische Gerechtigkeit (1933); Die Idee der Gerechtigkeit... (1953); Was ist Gerechtigkeit? (1953); Was ist Gerechtigkeit? (2ª ed., 1957); Die Illusion der Gerechtigkeit (1985). 
sociologia e crítica das ideologias, mas sempre os separando claramente dos estudos de teoria do direito.

Após a morte de Kelsen, em 1973, a atenção dos estudiosos concentrou-se sobretudo em suas obras de teoria do direito e naquelas de teoria política, enquanto tiveram menos difusão seus escritos de direito internacional e, principalmente, aqueles sobre a justiça ${ }^{3}$, não obstante as reedições e mesmo a publicação de obras póstumas sobre o tema.

Nas páginas seguintes, concentraremos a nossa atenção no escrito Das Problem der Gerechtigkeit $^{4}$, publicado em 1960 como apêndice à segunda edição da Reine Rechtslehre ${ }^{5}$ (KELSEN, 1960). A posição editorial já é significativa: em sua obra princeps de teoria do direito, o jurista não pode ignorar a justiça, mas o teórico puro do direito a coloca em posição claramente separada da discussão teórico-jurídica, que tem por objeto tão somente o direito positivo. Este deve ser estudado apenas do ponto de vista formal, prescindindo de seu conteúdo e, assim, também da valoração do ser justo ou não. Do ponto de vista editorial, a clara divisão entre doutrina pura do direito e teorias da justiça levou a publicar como obras autônomas a summa da doutrina pura do direito e o apêndice sobre a justiça ${ }^{6}$.

\section{KELSEN E O VALOR DA JUSTIÇA}

Pode-se admitir um único valor de justiça (que será, então, absoluto) ou vários em contraste entre si (que serão relativos). O direito positivo pode ser valorado em relação a esses valores de justiça, mas deste confronto não depende sua validade; ou seja, sua existência. Uma frase sintetiza os nexos entre a doutrina pura do direito e a justiça: "Uma doutrina positivista" não sustenta "que não haja justiça alguma, mas que, de fato, pressupõem-se muitas normas de justiça diferentes e em contraste umas com outras" (KELSEN, 1960, p. 403 apud LOSANO, 1975, p. 70). Um ordenamento jurídico pode, assim, ser qualificado como justo em relação a uma dessas normas, mas injusto diante de outra; portanto,

\footnotetext{
${ }^{3}$ Em 1998, atualizava esta literatura secundária com alguns títulos italianos, mas constatava que, em Kelsen, a justiça "é uma presença indireta: é a presença de um convidado indesejado, que se decidiu a deixar fora da porta, na qual bate incessantemente." (LOSANO, 1998, p. 12 e nota 8).

${ }^{4} \mathrm{O}$ problema da justiça. [N. do T.]

${ }^{5}$ Doutrina pura do direito. Optou-se pelo termo doutrina ao invés de teoria para manter a coerência com o autor, que assim traduz para o italiano a palavra alemã Lehre. A tradução consagrada no Brasil, porém, é teoria pura do direito. [N. do T.]

${ }^{6}$ Assim se passou nas edições italianas editadas por mim: cf. prefácio à nova edição de Il problema della giustizia (1998); também a introdução de Il problema della giustizia (1975); La dottrina pura del diritto e la giustizia (1981); La teoría pura del derecho y la justicia (1992); introdução à edição italiana de O problema da justiça (1993).
} 
uma teoria positivista do direito reconhece o fundamento de validade de um ordenamento jurídico positivo não em uma das numerosas normas de justiça, [... mas sim] em uma norma hipotética, isto é, pressuposta pelo pensamento jurídico, com base na qual se ordenam os comportamentos e se devem tratar os homens em conformidade com uma constituição que seja historicamente a primeira e eficaz em suas grandes linhas. [...] Discutindo acerca da validade do direito positivo, não se examina outra norma além da fundamental; em particular, não se examina norma de justiça alguma (KELSEN, 1970, p. 404 apud LOSANO, 1975, p. 71. Grifos nossos) $)^{7}$.

Esta frase exprime o relativismo ético que inspira a doutrina pura do direito, mas contém in nuce dois dos temas objeto das principais críticas opostas a essa doutrina (aqui apenas invocadas). Em primeiro lugar, a teoria que declara ter por objeto exclusivamente o direito positivo se funda sobre uma norma fundamental não instituída por órgãos constitucionais, mas pensada pelo jurista; em segundo lugar, a teoria fundada sobre o radical dualismo entre mundo normativo e natural, entre ser e dever-ser, funda a validade do ordenamento jurídico (pertencente ao mundo do dever-ser) sobre a eficácia da constituição historicamente primeira (pertencente ao mundo do ser). Basta assinalar, aqui, essas duas dificuldades da doutrina pura do direito, que aprofundei alhures (cf. LOSANO, 1975; Id., 1981; Id., 1982), e voltar ao problema da justiça na doutrina kelseniana.

Essa visão filosófica geral reflete-se na estrutura de Das Problem der Gerechtigkeit (KELSEN, 1960), que, a meu juízo, pode ser considerado o escrito mais completo de Kelsen sobre os nexos entre ordenamento jurídico e justiça. Divide-se em duas partes de igual peso, a primeira dedicada às várias normas de justiça e a segunda, à crítica do jusnaturalismo. Naquela, partindo dos nexos entre ética e justiça, constata que a valoração de "justo" ou "injusto" se refere sempre a um dado de fato - Seins-Faktum ${ }^{8}$ (Ibid, p. 4, p. 358), mas não se pode referir ao confronto entre uma norma de justiça e outra de direito positivo: "Isso pressupõe, porém, que se considerem ao mesmo tempo válidas tanto a norma de justiça quanto a norma de direito positivo". Mas a validade de uma delas falha "quando as duas

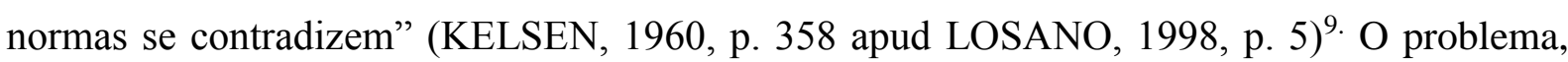
que Kelsen resolve separando-o de toda consideração de fato e recorrendo à norma fundamental, transfere-se, assim, ao âmbito da validade do direito positivo. Para a doutrina

\footnotetext{
7 "Eine positivistische Rechtslehre erkennt den Geltungsgrund einer positiven Rechtsordnung nicht in irgendeiner der vielen Gerechtigkeitsnormen [..., sondern] in einer hypothetischen, das heißt im Rechtsdenken vorausgesetzten Grundnorm, derzufolge man sich so verhalten, Menschen so behandeln soll, wie es einer historisch ersten, im großen und ganzen wirksamen Verfassung entspricht. [...] Sofern die Geltung des positiven Rechts in Frage steht, kommt keine andere Norm als diese Grundnorm, kommt insbesondere keine Gerechtigkeitsnorm in Betracht".

${ }^{8}$ Fato real, existente no tempo e no espaço; membro da realidade. (KELSEN, 1962, p. 24). [N. do R.]

9 "Dies setzt voraus, daß die Gerechtigkeitsnorm und die Norm des positiven Rechts zu gleicher Zeit als gültig angesehen werden. Dies ist aber nicht möglich, wenn beide Normen zueinander in Widerspruch, das heißt: miteinander in Konflikt stehen".
}

Revista da Faculdade de Direito - UFPR, Curitiba, vol. 59, n. 2, p. 31-45, 2014. 
pura, o problema da validade do direito está fora do mundo dos valores. Justamente com base nessa posição a citada doutrina entra em contraste com sua maior antagonista, a doutrina do direito natural, que, ao contrário, tem por válido um ordenamento positivo apenas se conforme a um valor de justiça.

Kelsen distingue os valores relativos do valor absoluto de justiça e, em harmonia com sua opção antimetafísica, propõe um exame científico das teorias da justiça: "Como científica, tal tratativa não deve decidir o que é justo, ou seja, prescrever como é necessário tratar os homens, mas sim descrever o que, de fato, é considerado justo, sem, porém, identificar-se com um dos valores descritos” (KELSEN, 1960, p. 365 apud LOSANO, 1998, p. 15) ${ }^{10}$. Kelsen adota uma posição avalorativa análoga no que diz respeito à interpretação (LOSANO, 1981). A descrição dos valores de justiça inicia-se com as normas de justiça de tipo racional, aquelas "estatuídas por atos humanos, postos em existência no mundo da experiência" e, assim, compreensíveis "por meio do intelecto humano", ou seja, racionais (KELSEN, 1960, p. 366 apud LOSANO, 1998, p. 16) ${ }^{11}$.

Neste ponto, desfaz-se o catálogo dos valores de justiça clássicos ${ }^{12}$, que, justamente por serem numerosos, têm um valor parcial, relativo. Todavia, para Kelsen, que recorre a Platão, a busca pela justiça coincide com “a indestrutível busca pela felicidade” própria ao ser humano; "mas nenhuma justiça apenas relativa, apreensível com a razão humana, pode alcançar esse fim. [...] A justiça de que todo o mundo está à procura é, então, a justiça absoluta. Ela é um ideal irracional porque pode derivar apenas de uma autoridade transcendente, isto é, de Deus" (KELSEN, 1960, p. 401 apud LOSANO, 1998, p. 66) ${ }^{13}$.

A justiça absoluta é transferida ao além e está nas mãos de Deus, razão pela qual pressupõe a fé (e não a razão). Sobre a terra, ao contrário, deve-se contentar com a justiça relativa garantida pelo ordenamento jurídico positivo, ou seja, com a situação "de paz e

\footnotetext{
10 "Als Wissenschaft hat sie nicht zu entscheiden, was gerecht ist, das heißt vorzuschreiben, wie man Menschen behandeln soll, sondern zu beschreiben, was tatsächlich als gerecht gewertet wird, ohne sich selbst mit einem dieser Werturteile zu identifizieren".

11 "daß sie als durch menschliche, in der Welt der Erfahrung gesetzte Akte statuiert gedacht und von der menschlichen Vernunft, das heißt rational begriffen werden können".

12 Para uma primeira comparação, vejam-se, por exemplo, Giorgio del Vecchio (1924), com numerosas reedições (originalmente: La giustizia. Discorso del prof. Giorgio Del Vecchio per l'inaugurazione dell'anno accademico 1922-23, também publicado na Rivista internazionale di filosofia del diritto, em 1923, fasc. 2-4); Chaïm Perelman (1945); e os comentários de Bobbio (1952, p. 16-33).

13 "unzerstörbares Verlangen nach Glück"; "Keine bloß relative, menschlicher Vernunft begreifbare Gerechtigkeit kann dies Ziel erreichen. [...] Die Gerechtigkeit, nach der die Welt schreit, ist daher die absolute Gerechtigkeit. Sie ist ein irrationales Ideal. Denn sie kann nur von einer transzendenten Autorität, nur von Gott ausgehen".
} 
segurança que qualquer deles garante em maior ou menor medida" (Ibid., loc. cit.) ${ }^{14}$. De fato, todo ordenamento jurídico se propõe a realizar um ideal de justiça, mas, como se disse, desse valor não depende sua validade.

\section{JUSTIÇA E CERTEZA DO DIREITO}

O jurista tende a se questionar se certo fato é ou não subsumível a certa norma, mas não se é justo que aquele fato seja ou não submetido àquela norma. Essa consideração puramente formal do direito é "a postura inconsciente habitual dos juristas", trazida por Kelsen "em plena e clara consciência" à doutrina pura do direito. Segundo Bobbio, o jurista assume tal postura inconscientemente juspositivista porque "o ideal do jurista é a certeza, não a justiça do direito, tarefa esta de filósofos, políticos, legisladores" (BOBBIO, 2012, p. 52 et seq.).

A busca pela certeza do direito nasce do propósito do súdito de se defender do arbítrio do soberano: a história jurídica do Iluminismo é aquela de um percurso do arbítrio soberano à certeza do direito. Ao fim deste trajeto, erige-se o Estado moderno com sua constituição, com a divisão de poderes e com um ordenamento normativo composto por normas gerais, abstratas e rígidas. A certeza do direito nasce da interseção desses elementos.

As normas jurídicas são gerais porque dirigidas a grupos específicos de cidadãos; abstratas porque se referem a ações tipificadas, isto é, definidas por meio de características formais; rígidas porque podem ser modificadas apenas por um procedimento preestabelecido pela constituição e atribuído ao único órgão competente ao exercício do poder legislativo. A divisão dos poderes impede que o juiz substitua o legislador, criando direito para o caso concreto (como pregava, ao contrário, o Movimento do Direito Livre), e que o poder executivo emane normas em concorrência com as leis formais (como ocorre nos Estados autocráticos regidos por governos ditos fortes). Também o poder legislativo encontra limites nas linhas traçadas pela lei fundamental, pela constituição rígida: violando-as, incorre em anulação de seu ato pela corte constitucional.

Passando do direito positivo à ciência jurídica, esta, em geral, enfrenta o problema da interpretação partindo da noção de completude, isto é, da exclusão de lacunas do ordenamento. ${ }^{15} \mathrm{Em}$ caso de incerteza, instrumentos como a interpretação analógica, a analogia, ou os princípios gerais do ordenamento (art. 12, disposição preliminar do Código

\footnotetext{
${ }^{14}$ [relative Gerechtigkeit] "in dem von ihr mehr oder weniger gesicherten Friedens- und Sicherheitszustand erblickt werden kann".

${ }^{15}$ Com referência ao autor tratado no item 4, cf. COSSIO, 2005.

Revista da Faculdade de Direito - UFPR, Curitiba, vol. 59, n. 2, p. 31-45, 2014.
} 
Civil italiano) permitem suprir a lacuna aparente. Da mesma forma, as fontes extraestatais do direito - como o costume e o dito "direito dos particulares" (SFORZA, 1929) - são reconduzidas ao conjunto de normas por meio de um reenvio explícito. Em outros termos, o ordenamento possui capacidade de autointegração, tornando-se sempre e de qualquer forma completo. Tal completude é, também ela, uma condição à certeza do direito.

Obviamente, o princípio da autointegração do ordenamento não é aceito sem exceções, que, por sua vez, impõem certos limites à criatividade extranormativa. Por exemplo, o art. $1^{\circ}$ do Código Civil suíço - talvez o caso mais citado de heterointegração - estabelece que o juiz deve ater-se primeiro à lei, depois ao costume, ou, "na falta deste", seguir "a regra que adotaria como legislador"; porém, mesmo neste caso, deve ater-se "à doutrina e à jurisprudência mais reconhecidas" ${ }^{16}$.

As posições práticas e doutrinárias mais adversas à doutrina da certeza provêm do mundo do Common Law. Segundo o juiz Oliver Wendell Holmes (1841-1935), o direito não é lógica, mas experiência:

The life of the law has not been logic: it has been experience. The felt necessities of the time, the prevalent moral and political theories, intuitions of public policy, avowed or unconscious, even the prejudices which judges share with their fellowmen, have had a good deal more to do than the syllogism in determining the rules by which men should be governed. (HOLMES, 1881, p. 1). ${ }^{17}$

Como consequência, para Holmes (1897, p. 457), a certeza é apenas uma ilusão: "Certainty generally is illusion, and repose is not the destiny of man" ${ }^{18}$. Para o juiz Jerome Frank (1889-1957), o desejo de certeza é próprio aos direitos primitivos e funda-se sobre a exigência psicanalítica da necessidade, por parte do filho, da autoridade do pai e da necessidade do povo primitivo de uma autoridade indiscutível (FRANK, 2009). Ao contrário, o direito moderno deve ser caracterizado pela adaptabilidade às exigências sociais mutáveis.

\footnotetext{
${ }^{16}$ Codice Civile Svizzero, 1907, Titolo preliminare: “(1) La legge si applica a tutte le questioni giuridiche alle quali può riferirsi la lettera od il senso di una sua disposizione. (2) Nei casi non previsti dalla legge il giudice decide secondo la consuetudine e, in difetto di questa, secondo la regola che egli adotterebbe come legislatore. (3) Egli si attiene alla dottrina ed alla giurisprudenza più autorevoli”. Código Civil Suíço, 1907, Título preliminar: “(1) A lei se aplica a todas as questões jurídicas às quais se pode referir a letra ou ou o sentido de uma de suas disposições. (2) Nos casos não previstos pela lei o juiz decide segundo o costume e, na falta dele, segundo a regra que adotaria como legislador. (3) Ele se atém à doutrina e à jurisprudência mais reconhecidas." [N. do T.]

17 "A existência do direito não tem sido lógica: tem sido experiência. As necessidades sentidas em cada tempo, as teorias morais e políticas prevalentes, intuições de política pública, confessas ou inconscientes, mesmo os preconceitos que os juízes compartilham com seus companheiros, tiveram muito maior influência que o silogismo ao determinar as regras pelas quais os homens devem ser governados." [N. do T.]

18 “Certeza geralmente é ilusão, e repouso não é o destino do homem". Ou ainda, com intraduzível jogo de palavras, conforme publicado na Harvard Law Review (1918): "Certitude is not the test of certainty. We have been cocksure of many things that were not so". [N. do T.]

Revista da Faculdade de Direito - UFPR, Curitiba, vol. 59, n. 2, p. 31-45, 2014.
} 
Mas o mundo do Common Law é regido pelo princípio do precedente jurisprudencial, fundando-se sobre normas individuais e flexíveis e, assim, é radicalmente diverso do mundo europeu continental, fundado sobre normas gerais e abstratas. Também este, todavia, conheceu momentos em que as teorias da jurisprudência dos interesses e do direito livre antepuseram a adaptabilidade à certeza do direito: mas vale notar que isso ocorreu em momentos de grandes transformações sociais, nos quais o direito positivo rígido estava em descompasso com a evolução social ${ }^{19}$. Em geral, os juristas europeus continentais aceitam com frequência tacitamente - o modelo legalista de ordenamento e, com ele, o Estado de direito com seu conjunto de normas.

O funcionamento coordenado desse aparato estatal e doutrinário garante ao cidadão a certeza da qualificação jurídica das próprias ações. O Estado que lhe garante tal certeza é o Estado de Direito, cuja estrutura está estritamente ligada àquela da democracia.

Em outro escrito, Bobbio - influenciado também "pela deformação profissional de quem lecionou por decênios em uma faculdade de direito" - propõe-se a individualizar as características indispensáveis para que um regime possa definir-se democrático, concentrando sua atenção no elemento formal das "regras do jogo": "Por regime democrático se entende primariamente um conjunto de regras de procedimento para a formação de decisões coletivas [isto é, as leis], em que é prevista e facilitada a participação mais ampla possível dos interessados" (BOBBIO, 1995, p. XXII et seq.) ${ }^{20}$; ou melhor, regras "que estabelecem quem é autorizado a tomar as decisões coletivas e com quais procedimentos" (Ibid., p. 4) (1) $^{21}$

A concepção de Estado de direito reflete-se de vários modos na doutrina kelseniana. Antes de tudo, também na doutrina pura do direito o ordenamento jurídico visa a realizar um valor: a legalidade é perseguida tacitamente (mas, como se disse, a validade do ordenamento não se funda sobre esse valor). Com efeito, Kelsen tem implicitamente em vista o Estado democrático. Passando da teoria jurídica à política, a importância atribuída por Kelsen ao Estado de direito explica sua visão da democracia como procedimento. Enfim, passando à metateoria do direito, o vínculo estreito entre a doutrina pura e o Estado de direito fruto do Iluminismo explica porque ela deve ser compreendida não apenas como uma teoria geral do direito, mas principalmente como uma teoria do direito europeu continental da era industrial $(\text { LOSANO, 2007) })^{22}$.

\footnotetext{
${ }^{19}$ Para tais movimentos, remeto à literatura citada em Losano (2002, Vol. 2, p. 114-54).

${ }^{20}$ Cf. prefácio da edição de 1984. A edição de 1995 não traz o subtítulo Una difesa delle regole del gioco.

${ }^{21}$ Assim no ensaio de 1984.

$22 \mathrm{O}$ estudo dos sistemas jurídicos extraeuropeus, para mim, permitiu-me verificar este limite histórico e geográfico da doutrina pura do direito.

Revista da Faculdade de Direito - UFPR, Curitiba, vol. 59, n. 2, p. 31-45, 2014.
} 


\section{UM EXEMPLO DE CONTRASTE ENTRE TEORIAS OPOSTAS DA JUSTIÇA: KELSEN E COSSIO}

Em 1949, durante sua viagem à América do Sul, Kelsen proferiu várias conferências na Argentina a convite da Faculdade de Direito, da Ordem dos Advogados e do Instituto de Filosofia Jurídica e Social de Buenos Aires. A escolha das instituições anfitriãs já refletia a tentativa de equilibrar as forças peronistas e antiperonistas, com as quais se imbricavam as correntes pró-cossianas e antikelsenianas (e, portanto, pró-peronistas) e as correntes prókelsenianas e anticossianas (e, portanto, antiperonistas).

Com efeito, o mais importante filósofo do direito argentino era, então, Carlos Cossio (1903-1987), que concebia sua "teoria egológica do direito" (COSSIO, 1964, 2005) como a superação da doutrina pura kelseniana, muito citada na summa do pensamento do filósofo $\operatorname{argentino}^{23}$. Assim, convidar Kelsen a Buenos Aires visava, também, a fazer com que reconhecesse de alguma forma a teoria egológica do direito como o aperfeiçoamento da própria doutrina pura. Uma e outra, porém, eram tão incompatíveis quanto antagônicas as personalidades de seus dois autores.

Nessa linha, a viagem nascia sob o signo de tensões políticas e culturais que culminaram em 1952, quando Carlos Cossio publicou um volume incluindo a tradução ao espanhol das quatro conferências apresentadas por Kelsen (KELSEN; COSSIO, 1952), precedidas por uma introdução retomando o Balanço provisório redigido pelo mesmo Cossio como conclusão da visita de Kelsen à Argentina ${ }^{24}$. Esse volume, de fato, não reproduzia o original francês de Kelsen, como fora acordado; ao contrário, trazia na capa o nome de dois autores - Cossio e Kelsen - e, no texto, notas e comentários de Cossio ao escrito kelseniano.

Cossio tentava, assim, demonstrar publicamente que Hans Kelsen aceitara sua visão egológica da filosofia do direito. A esta manipulação Kelsen reagiu duramente, publicando uma nota de esclarecimento ${ }^{25}$ e requerendo ao editor que tirasse de circulação o livro em que - sem sua autorização - figurava seu nome como coautor. Dessa forma, chegou-se a uma

\footnotetext{
${ }^{23}$ Cf. COSSIO, 1964. Cf. também supra, nota 15 e infra, nota 32.

${ }^{24}$ Por causa destas intervenções no texto, as concepções expressas nesse volume precisam ser tratadas com particular circunspecção.

${ }^{25}$ A resposta de Kelsen vem publicada nas revistas em que havia circulado o Balanço provisório de Cossio: cf. por exemplo: La teoría pura del derecho y la teoría egológica. Respuesta al artículo de Carlos Cossio... (1953, p. 749-64); Teoría pura del Derecho y teoría egológica. Respuesta al artículo de Carlos Cossio... (1953, p. 169205) (o texto integral está disponível em: <http://www.juridicas.unam.mx/publica/librev/rev/facdermx/cont/10/pr/pr13.pdf>). Há também outra tradução para o espanhol, de Luis Legaz Lacambra, na Revista de Estudios Politicos (1953, n. 71, p. 3-39). Texto original: Reine Rechtslehre und Egologische Theorie. Antwort auf Carlos Cossio... (1953, p. 449-82). Revista da Faculdade de Direito - UFPR, Curitiba, vol. 59, n. 2, p. 31-45, 2014.
} 
inevitável ruptura entre os dois filósofos do direito e suas escolas, cujos reflexos são perceptíveis mesmo na literatura jusfilosófica atual.

Em sua ânsia por protagonismo, Cossio escrevia:

Creio que haja dois poderosos motivos para interpretar a visita de Kelsen [à Argentina...] apenas como um prólogo: o de uma bela epifania em que as vozes profundas do acompanhamento sinfônico provêm do generoso maestro, enquanto a execução da partitura, porém, deve ser modulada com tons argentinos [, de modo que] hoje há toda uma juventude com o coração inflamado pela egologia (KELSEN; COSSIO, 1952 apud SARLO, 2006, p. 971);

e ainda: "Em 1949, Buenos Aires contempla a morte da doutrina kelseniana da teoria pura do direito e sua ressurreição graças à interpretação egológica" (COSSIO, 1954, p. XI apud SARLO, ibid., p. 968). Em face desta áspera polêmica, pode ser útil examinar como Cossio interpretara a teoria da justiça de Kelsen.

Antes de tudo, é preciso tentar uma síntese quase impossível da teoria egológica de Cossio, filosofia jurídica de ampla inspiração eclética, ainda que com forte influência de Husserl e Heidegger: e a Husserl recorre Cossio para explicar a escolha do nome de sua teoria, que soa "surpreendente e insólito ao ouvido do jurista" (COSSIO, 1964, p. 26) ${ }^{26}$. Cossio refuta Max Scheler e Nicolai Hartmann porque, "em seu todo, considero a obra de ambos inaceitável pela natureza hipostática que apresentam" (Ibid., p. 87). Os autores mais citados, em ordem crescente, são Husserl, Heidegger, Kant ("el nervio vivo del actual pensamiento filosófico de Occidente" ${ }^{27}$ ) e, sobretudo, Kelsen, tanto que o mesmo Cossio adverte que a compreensão da teoria egológica "pressupõe certa familiaridade com o pensamento" desses autores, sem a qual se deve "limitar a apreender a ideia egológica de forma mais ou menos deficitária” (Ibid., p. 14 et seq.).

A teoria egológica é composta por uma série de subconjuntos que constituem, cada qual, uma parte do livro A teoria egológica do direito: a ontologia jurídica, ou seja, investigação sobre o ser do direito; a lógica jurídica formal, entendida como lógica peculiar ao pensamento jurídico; a lógica jurídica transcendental, entendida como teoria especial do conhecimento normativo, do conhecimento como compreensão da conduta jurídica; a axiologia jurídica pura, uma axiologia do comportamento jurídico, já que, para Cossio, o direito estuda a experiência humana, que é uma conduta e, como tal, desdobra-se sobre a base dos juízos de valor. Enfim, a gnosiologia do erro fornece os instrumentos para distinguir o conhecimento científico do direito de sua interpretação ideológica, isto é, errada. O conjunto

\footnotetext{
${ }^{26}$ Ego-logia é conhecimento do eu; Cossio (1964), porém, "seguindo o exemplo husserliano", antepõe o logos ao ego. Ademais, passa "do eu cognoscente ou teórico ao eu operante ou prático".

27 "...o nervo vivo do atual pensamento filosófico do Ocidente". [N.do T.]

Revista da Faculdade de Direito - UFPR, Curitiba, vol. 59, n. 2, p. 31-45, 2014.
} 
dessas linhas forma a teoria egológica do direito, que "busca analisar o direito como experiência específica", como "um objeto cultural cujo conhecimento exige uma intuição (em sentido husserliano), uma compreensão e um pensamento normativo". Cossio vai, portanto, além do conhecimento puramente racional ou científico do direito e sustenta "uma teoria gnosiológica, existencial e valorativa” (PISI DE CATALINI, 1991, p. 53), aproximando-se, inclusive, da teoria tridimensional do direito elaborada por Miguel Reale, o mais relevante filósofo do direito brasileiro do século $\mathrm{XX}^{28}$.

A relação ambivalente de Cossio com a doutrina de Kelsen reflete-se nas explicações que o próprio Cossio fornece acerca do desenvolvimento da parte formal no volume de 1964. Deveu-se à "discussão analítica da teoria pura do direito e [ao] enxerto desta devendo ter lugar na teoria egológica, desde o momento em que se tratava de absorver a teoria pura sem dar espaço à confusão de que uma e outra fossem a mesma coisa ou trabalhassem sobre a mesma base filosófica". O adversário fraco, afirma Cossio referindo-se a Kelsen, "é sempre o melhor adversário, e a verdade é que o tomar a doutrina pura do direito como o melhor adversário, para, de súbito, fazê-la servir como o melhor aliado, assumia o sentido de um movimento estratégico de grande ressonância" (COSSIO, 1964, p. 23 et seq.); ao fim desse "movimento estratégico" está "a absorção que a teoria egológica do direito faz da doutrina pura" (Ibid., p. 101) ${ }^{29}$. Conclusão de que Kelsen não era entusiasta.

$\mathrm{Na}$ obra de Cossio, a doutrina pura do direito é citada quase sempre com referência a noções jurídicas. É significativo que o nome de Kelsen esteja ausente das longas passagens sobre a justiça (Ibid., p. 562-630) ${ }^{30}$, enquanto em todo o livro Cossio comenta e critica Kelsen em temas específicos de teoria geral do direito, inclusive em trechos de notável extensão. Apenas um deles será agora submetido à análise.

A teoria egológica "toma da teoria pura a ideia da normatividade como pureza metodológica, sua abordagem analítica da norma, o enfoque dialético dos dualismos científicos do pensamento jurídico"; aceita-a, "em princípio, sem modificação alguma de seu conteúdo", porém, "modifica radicalmente" sua abordagem teórica, porque "para a teoria egológica o direito é a conduta como interferência intersubjetiva, não a norma” (Ibid., p. $101)^{31}$. Alterados dessa forma os axiomas de partida, torna-se inevitável a incompatibilidade recíproca das duas teorias e a recíproca incompreensão de seus autores. Numerosas outras

${ }^{28}$ O artigo de Marta Pisi de Catalini apresenta uma síntese do pensamento de Cossio e um confronto entre Cossio e Miguel Reale.

${ }^{29}$ No volume, a mais extensa tratativa das relações entre as duas teorias está nas p. 101-12.

${ }^{30}$ Situadas no capítulo La Axiología jurídica pura.

${ }^{31}$ As páginas 101-12 são dedicadas à discussão dessa relação complexa, mas sobretudo a um exame crítico de Algunas observaciones a la doctrina de Hans Kelsen (SOLER, 1943).

Revista da Faculdade de Direito - UFPR, Curitiba, vol. 59, n. 2, p. 31-45, 2014. 
passagens demonstram a atenção de Cossio à doutrina pura do direito, mas também a incompatibilidade entre as duas teorias: por questão de brevidade, vêm indicadas em nota ${ }^{32}$.

A recepção falha da teoria da justiça de Kelsen por Cossio está documentada pelo estudo específico sobre a teoria da justiça em Cossio de Héctor Hernández, que parte de axiomas filosóficos diversos tanto dos husserlianos de Cossio quanto dos neokantianos de Kelsen. O enfoque aristotélico-tomista de sua investigação é declarado já nas primeiras páginas: "Segui aqui, como desejo fazer em minha vida, o caminho espiritual de uma Tradição que culmina nos gênios de Aristóteles e São Tomás de Aquino" (HERNÁNDEZ, 1980, p. 16). Assim, resta bem pouco de Cossio - Hernández "refuta expressamente" (Ibid., p.15) a concepção egológica das fontes, da lógica e da norma - e menos ainda de Kelsen. Partindo de Aristóteles, Hernández considera que os seres humanos são iguais em abstrato, mas desiguais em concreto. Kelsen sustenta que a igualdade dos pontos de partida exige que todos recebam uma instrução adequada, o que Hernández refuta com estas palavras: "Portanto, a educação (estatal) deve adiantar-se e declarar obrigatórias as creches, e com isso a coletivização chega quase ao útero materno e se dissolve o grupo familiar" (Ibid., p.123) ${ }^{33}$. Ao mesmo escrito de Kelsen se refere para afirmar que, no autor, reconhece a existência de alguma coisa de "justo natural" na satisfação das necessidades primárias, como o alimento e o abrigo (Ibid., p. 165) ${ }^{34}$. Enfim, recordando a polêmica entre Kelsen e Cossio, destaca como "o Kelsen liberal" refuta a teoria de Cossio por partir este de premissas metafísicas. Ao contrário, o que Hernández reconhece como positivo em Cossio é "o haver reintroduzido o elemento valorativo no saber jurídico, contra seu ex-mestre Kelsen" e "o haver voltado a dar destaque à noção e à realidade da justiça" (Ibid., p. 163) ${ }^{35}$. A crítica de fundo que Hernández opõe a Cossio vale também contra Kelsen e torna inconciliáveis esses mundos filosóficos: o primeiro dos "aspectos tidos por negativos" em Cossio é, com efeito, "a ausência de uma Filosofia Geral e verdadeira, que sirva de fundamento a toda a temática jusfilosófica” (Ibid., p. 155) ${ }^{36}$. Verdadeira, para Hernández, significa "revelada"; e esse significado do termo verdade é de todo estranho ao pensamento kelseniano (LOSANO, 2013b, p. 33-47). Dada a heterogeneidade dos sistemas filosóficos de que partem Cossio, Hernández e Kelsen, a teoria da justiça deste permanece circunscrita ao âmbito da doutrina pura do direito.

\footnotetext{
${ }^{32}$ Cf. COSSIO, 1964, p. 358-65, 382-90, 390-400, 417-35, 435-7, 437-45, 445-8, 449-56.

${ }^{33}$ Nota 202 da obra de Hernández, referindo-se a KELSEN, 1966, p. 16.

${ }^{34}$ Nota 275 da obra de Hernández, referindo-se a KELSEN; COSSIO, 1952, p. 117. Cf. Nota 25.

${ }^{35}$ Destaques de Hernández.

${ }^{36}$ Destaque de Hernández. 


\section{REFERÊNCIAS}

BOBBIO, Norberto. Il futuro della democrazia. Torino: Einaudi, 1995.

. Sulla nozione di giustizia. In: Archivio giuridico, 1952, n. 1-2, p. 16-33.

. Teoria della giustizia. Lezioni di filosofia del diritto, 1953. Torino: Aragno, 2012.

COSSIO, Carlos. La plenitud del ordenamiento jurídico. Buenos Aires: Los Andes, 2005. 316 p. Reimpressão da $2^{\mathrm{a}}$ ed. de 1947; $1^{\mathrm{a}}$ ed.: 1939.

La teoría egológica del derecho y el concepto jurídico de libertad. Buenos Aires: Abeledo-Perrot, 1964. 821 p. $1^{\text {a }}$ ed.: 1944.

La valoración jurídica y la ciencia del derecho. Buenos Aires: Acayú, 1954.

DEL VECCHIO, Giorgio. La giustizia. Bologna: Nicola Zanichelli, 1924, 79 p.

La giustizia: discorso del prof. Giorgio Del Vecchio per l'inaugurazione dell'anno accademico 1922-23. Roma: Tipografia fratelli Pallotta, 1923. 43 p.

La giustizia: discorso del prof. Giorgio Del Vecchio per l'inaugurazione dell'anno accademico 1922-23. Rivista internazionale di filosofia del diritto, 2-4, 1923.

FRANK, Jerome. Law and the Modern Mind. New Brunswick: Transaction Publishers (N. J.), 2009. $1^{\text {a }}$ ed.: New York: Brentano, 1930.

HERNANDEZ, Hector. La justicia en la teoría egológica del derecho. Buenos Aires: Ed. Abeledo Perrot, 1980.

HOLMES, Oliver Wendell. Natural Law. 32 Harvard Law Review 40-1, 1918.

The Common Law. Boston: Little \& Brown, 1881.

The Path of the Law. 10 Harvard Law Review 457, 1897.

KELSEN, Hans; COSSIO, Carlos. Problemas escogidos de la teoría pura del derecho. Teoría egológica y teoría pura. Buenos Aires: Editorial Guillermo Kraft, 1952. 158 p.

KELSEN, Hans. Il problema della giustizia. Torino: Einaudi, 1998.

Das Problem der Gerechtigkeit. In: Reine Rechtslehre. Wien: Franz Deuticke, 1960.

. Die Idee der Gerechtigkeit nach den Lehren der christlichen Theologie. Eine

kritische Analyse von Emil Brunners 'Gerechtigkeit'. In: Studia Philosophica 13 (Basilea). Band, 1953.

Die Illusion der Gerechtigkeit. Eine kritische Untersuchung der Sozialphilosophie Platons, im Auftrag des Hans Kelsen-Instituts aus dem Nachlaß herausgegeben von Kurt Ringhofer und Robert Walter. Manz, Wien, 1985, 458 p. 

1933.

Die platonische Gerechtigkeit. In: Kant-Studien. Philosophische Zeitschrift 38. Band,

La teoría pura del derecho y la teoría egológica. Respuesta al artículo de Carlos Cossio, 'Teoría egológica y teoría pura. Balance provisional de la visita de Kelsen a la Argentina'. La Ley, 1953, p. 749-64.

. O problema da justiça. São Paulo: Martins Fontes, 1993.

Qué es la justicia. Córdoba (Argentina): Universidad Nacional de Córdoba, 1966.

Reine Rechtslehre. Mit einem Anhang: Das Problem der Gerechtigkeit. Zweite, völlig neu bearbeitete und erweiterte Auflage. Wien: Franz Deuticke, 1960.

Reine Rechtslehre und Egologische Theorie. Antwort auf Carlos Cossio 'Egologische Theorie und Reine Rechtslehre, eine vorläufige Bilanz von Kelsens Besuch in Argentinien'. Österreichische Zeitschrift für öffentliches Recht, V, 1953, p. 449-82.

Teoría pura del Derecho y teoría egológica. Respuesta al artículo de Carlos Cossio: 'Teoría Egológica y Teoría Pura (Balance provisional de la visita de Kelsen a la Argentina)'. Tradução de Eduardo Garcia Máynez. Revista de la Facultad de Derecho de México, 1953, p. 169-205. Disponível

em: <http://www.juridicas.unam.mx/publica/librev/rev/facdermx/cont/10/pr/pr13.pdf >. Acesso em 12 abr. 2013.

Teoría pura del Derecho y teoría egológica. Respuesta al artículo de Carlos Cossio: 'Teoría Egológica y Teoría Pura (Balance provisional de la visita de Kelsen a la Argentina)'. Tradução de Luis Legaz Lacambra. Revista de Estudios Politicos (Madrid), Settembre Ottobre 1953, n. 71, p. 3-39.

. Théorie pure $d u$ droit. Traduction française de la $2^{\mathrm{e}}$ édition de la $<<$ Reine Rechtslehre>> par Charles Eisenmann. Paris: Dalloz, 1962.

.Was ist Gerechtigkeit?, Franz Deuticke, Wien 1953. IV, 47 Seiten (2a ed., 1957).

. 'Was ist Gerechtigkeit?' Vortrag, gehalten bei der Sitzung der Wiener Juristischen Gesellschaft vom 11. Februar 1953, Juristische Blätter 75. Jahrgang, 1953.

LOSANO, Mario G. Das Verhältnis von Geltung und Wirksamkeit in der Reinen Rechtslehre. In: Die Reine Rechtslehre in wissenschaftlicher Diskussion. Wien: Manz, 1982, p. 82-96.

Forma e realtà in Kelsen. Milano: Comunità, 1981.

. Il rapporto tra validità ed efficacia nella dottrina pura del diritto. In: Sociologia del diritto, VIII, 1981, n. 2, p. 5-23.

. Teoría pura del derecho: evolución y puntos cruciales. Bogotá: Editora Temis, 1992. 
Hans Kelsen. Relativismo e verità nel diritto e nella politica. In: Antonella Besussi (Ed.), Verità e politica. Filosofie contemporanee. Roma: Carocci, 2013b.

. I kritikì theorisi tis dikaiosynis ston Kelsen. In: Hans Kelsen i diachronikotita tou pneymatos sto nomiko kai koinoniologiko toy ergo. Athinai: Dieythynasi - Epiméleia Nikitas Aliprandis, Ekdoseis Papazisi, 2013a.

Os grandes sistemas jurídicos. Introdução aos sistemas jurídicos europeus e extraeuropeus. São Paulo: Martins Fontes, 2007. 677 p.

Sistema e struttura nel diritto. Vol. 2 - Il Novecento. Milano: Giuffrè, 2002.

PERELMAN, Chaïm. De la justice. Bruxelles: Office de publicité, 1945, 81 p.

PISI DE CATALINI, Marta. La teoría egológica de Carlos Cossio y el tridimensionalismo jurídico de Miguel Reale. Disponível em: <http://www.ffyl.uncu.edu.ar/IMG/pdf/05_vol_0809_catalini.pdf>. 1991. Acesso em: 12 abr. 2013.

SARLO, Oscar. La gira sudamericana de Hans Kelsen en 1949: el 'frente sur' de la teoría pura. In: Gregorio Peces-Barba - Javier de Lucas (Org.). El Derecho en Red. Estudios en Homenaje al Profesor Mario G. Losano. Madrid: Dykinson, 2006.

SFORZA, Widar Cesarini. Il diritto dei privati. Roma: Sampaolesi, 1929. 84 p. $2^{\text {a }}$ ed.: 1963.

SOLER, Sebastián. Algunas observaciones a la doctrina de Hans Kelsen. Boletín de la Facultad de Derecho y Ciencias Sociales de la Universidad Nacional de Córdova, 1943, año VII, números 3-4, p. 286-311.

\section{THE VALUE OF JUSTICE IN KELSEN'S WORK}

ABSTRACT: Discussing the value of justice in Kelsen's work, this article aims to expound an argument which analyses the mentioned value through the epistemological prism adopted by the specified law theorist, especially in his Pure Theory of Law. Even though he has written essays on politics, theory of justice, and so on, they have not been considered part of his legal theory since it was based on a restricted understanding of law as legal validity. According to it, even if reflections on justice are of great importance to philosophy, morals and politics, they have no significance to law and its pure theory.

KEYWORDS: Kelsen. Legal Validity. Pure Theory of Law. Value of Justice.

Recebido: 25 de novembro de 2013

Aprovado: 18 de agosto de 2014 